\title{
CONTENDAS DE SENTIDOS: ESTRATÉGIAS DE MIDIATIZAÇÃO DA DOENÇA DO EX- PRESIDENTE LULA
}

\author{
SENSES OF CONTENTION: \\ STRATEGIES MEDIATIZATION OF ILLNESS OF FORMER PRESIDENT \\ LULA \\ SENTIDOS DE LA DISCORDIA: \\ ESTRATEGIAS DE MEDIATIZACIÓN DE LA ENFERMEDAD DEL EX \\ PRESIDENTE LULA
}

\author{
Antônio Fausto Neto \\ UNISINOS \\ afaustoneto@gmail.com \\ Aline Weschenfelder \\ UNISINOS \\ alinewes@gmail.com
}

\section{Resumo}

A doença da qual foi acometido o presidente Lula, não pairou em "zonas de sombras", não foi confiada a porta-voz e nem teve o trabalho de sua mediação regulada pelas mídias. Foi um acontecimento cujos processos de produção e de circulação estiveram permeados por lógicas e operações de midiatização, mas a partir de apropriação feitas pela "ação comunicativa" do Instituto Lula. É a partir de suas estratégias que o acontecimento sobre a enfermidade circula entre "novas" e "velhas" mídias; é traduzido para temporalidades dos regimes de discursividades das mídias semanais, e se desloca para os sites noticiosos onde os internautas intervem através da esfera dos comentários. A estratégia não se limitou a "eclosão da enfermidade", mas também envolveu "a antecipação dos seus efeitos", através da midiatização da cenas nas quais Lula se desfaz da barba e do bigode, ato que tem como testemunha - e o seu principal operador - o fotógrafo do presidente. Se, sobre Tancredo Neves especulou-se sobre sua causa mortis, a enfermidade de Lula não fica na penumbra e nem nas mãos dos plantonistas. É ele quem, por via de operações tecno-discursivas, a escancara. E, dela cuida, cercado é verdade , por seu bunker midiático.

Palavras-chave: Lula, Enunciação, Circulação, Discursos, Sentidos, Enfermidade

\section{Abstract}

The illness that undertook President Lula did not lay in "dark zones", was not confided to a 
spokesperson nor had its mediation work regulated by the media. It was a happening which had its production and circulation processes permeated by mediatization logics and operations, but these took place through appropriations conducted by the "communicative action" of Instituto Lula (Lula Institute). It is through its strategies that the disease happening circulates between the "new" and "old" media; it translates into temporalities of the discursivity regimes of the weekly media and moves into news websites in which Internet users intervene through the comments sphere. The strategy was not limited to the "outbreak of the disease", but also involved "the anticipation of its effects" through the mediatization of the scenes in which Lula's beard and mustache are taken away, an act witnessed - and operated chiefly - by the president's photographer. If much was speculated about Tancredo Neves's cause of death, Lula's illness does not stand in the shadows nor in the hands of the physicians either. It is himself who, by techno-discursive operations, opens it wide and takes care of it surrounded, it is true, by his media bunker.

Keywords: Lula, Enunciation, Circulation, Discourses, Senses, Illness

\section{Resumen}

La enfermedad a la cual fue acometido el presidente Lula, no pairó en "zonas de sombras", no fue confiada a un portavoz y ni tuvo su mediación regulada por las medias. Fue un acontecimiento cuyos procesos de producción y de circulación estuvieron permeados por lógicas y operaciones de mediatización, pero a partir de apropiaciones hechas por la "acción comunicativa" del Instituto Lula. Es a partir de sus estrategias que el acontecimiento sobre la enfermedad circula entre "nuevos" y "viejos" medias; es traducido para temporalidades de los regímenes de discursividades de los medias semanales, y se desplaza para las páginas webs informativas donde los internautas intervienen a través de la esfera de los comentarios. La estrategia no se limitó a la "eclosión de la enfermedad", pero también envolvió "la anticipación de sus efectos", a través de la mediatización de las escenas en las cuales Lula se deshace de la barba y del bigote, acto que tiene como testigo - y su principal operador - el fotógrafo del presidente. Si, sobre Tancredo Neves se especuló sobre su causa mortis, la enfermedad de Lula no queda en la penumbra y ni en las manos de los médicos de plantón. Es él quien, por vía de operaciones tecno-discursivas, la muestra. Y, de ella cuida, cercado es verdad, por su bunker mediático.

Palabras clave: Lula, Enunciación, Circulación, Discursos, Sentidos, Enfermedad

\section{Nota Introdutória}

$\mathrm{O}$ câncer que acomete o ex-presidente Lula eclode numa complexa "realidade midiática" (Luhmann, 2005), transcende a "topografia" dos meios na medida em que é, constituída no ambiente da midiatização, por lógicas e operações midiáticas, se expande - via processos discursivos - para os âmbitos e práticas das instituições e dos atores sociais. A 
enfermidade do ex-presidente eclode, enquanto acontecimento, através de estratégias midiáticas acionadas por uma instituição política, o Instituto Lula ${ }^{1}$, desloca-se para o ambiente das mídias propriamente dita, bifurcando-se em velhos e novos meios, e disseminando-se para o universo da recepção, cujos comentários proliferam em sites jornalísticos de diversas naturezas. Como resultante da atividade de um complexo processo de produção e de circulação de discursos, a enfermidade se instala numa "zona de contatos", constituída por estas três instâncias e as possibilidades de sua inteligibilidade resultam de transações e operações enunciativas que se fazem neste contexto do trabalho técnicodiscursivo. Neste artigo são descritas estratégias discursivas de duas fases da produção/disseminação da enfermidade, constituída de eventos que são midiatizados no período de 29/10 a 16/11 de 2011, e que aqui recebem, respectivamente, como nomeação; a eclosão da enfermidade e a antecipação dos efeitos quimioterápicos. A primeira fase - a “eclosão da enfermidade" - envolve a existência de quatro eventos: o primeiro, no qual o Instituto Lula antecipando-se ao trabalho das mídias jornalísticas, põe em circulação (29/10) através do seu site, e numa mensagem de sete linhas, o primeiro informe sobre a enfermidade. O título da mensagem já nomeia a natureza da doença, informando que "Lula é diagnosticado com câncer na laringe". Na mesma, institui a "zona de contatos", ao oferecer possibilidades de acesso de receptores, propondo: "para enviar mensagens para o ex-presidente foi criado o email saudelula@icidadania.org”. O segundo evento trata do desencadeamento da circulação, através do site jornalístico G1, das "Organizações Globo". Sua intervenção discursiva não especifica a doença de Lula, mas anuncia o tratamento a que vai ser submetido - a quimioterapia -; chama atenção para a existência de um tumor que afeta a laringe do expresidente. O informe adianta um outro detalhe: o sintoma revelou-se através de uma "rouquidão acima do normal", além de dores na garganta; para tanto apóia tal registro numa outra referência, que é o boletim médico emitido. O terceiro evento é constituído por comentários de internautas deste mesmo site, que são divulgados (em número de 114), se configurando como espaço de acesso e de acoplamento dos receptores ao processo de

\footnotetext{
${ }^{1}$ Órgão de assessoria política criado pelo ex-presidente Lula, após sua saída do governo, com o objetivo de buscar de soluções para os problemas estruturais da realidade social brasileira, voltando-se para causas políticas e sociais no Brasil e no exterior. http://www.icidadania.org/
} 
circulação do acontecimento. E o quarto, a entrada em cena das instituições jornalísticas que, tendo sua "vocação mediadora" deslocada por uma operação midiática, tecida através de uma instituição de assessoria política. O IL promete dizer algo mais sobre a enfermidade, inclusive penetrar nos "bastidores da enfermidade".

A segunda fase (16/11) - a antecipação dos efeitos quimioterápicos - se desdobra em dois eventos específicos: o primeiro, se constituiu a partir de mais uma intervenção do Instituo Lula, que mediante operações discursivas do seu próprio staff de comunicação, exibe em seu site imagens nas quais registra o momento em que a esposa de Lula corta o cabelo e barba do ex-presidente. A operação midiática cumpre dupla "estratégia de antecipação": a dos efeitos quimioterápicos, uma vez que os mesmos incidiriam sobre o corpo de Lula e a anunciabilidade deste fato, feita por uma instância não midiática que, desta forma se antecipa ao anuncio, não deixando que o mesmo seja feita, em primeira mão pela instância jornalística.

Este processo de midiatização gera um novo fluxo de produção e circulação da enfermidade, enquanto acontecimento: O IL, ao roubar o "lugar de fala" das mídias jornalísticas, bem como a sua possibilidade de "dizer primeiro", esvazia seu status de "elo de contato" entre o mundo médico- político e a sociedade. Porém, colocadas na condição de "receptores do acontecimento", as mídias jornalísticas, através de operações autorreferenciais, afloram outros sentidos sobre a doença; e os receptores fazem do fato, uma contenda que transcende a enfermidade em si, na qual se manifestam discursivamente, através de diferentes imaginários: desde os atos de solidariedade à pugna política.

\section{Fase 1- A eclosão da enfermidade}

\section{a) A "gênese"}

O primeiro registro sobre a enfermidade nasce no site do Instituto Lula, que em nota de sete linhas, anuncia sua "eclosão" da doença: "Lula é diagnosticado com câncer na laringe" (Instituto Lula, 29/10/2011). Minutos depois, o portal G1, site de notícias da emissora de televisão brasileira Globo ${ }^{2}$, dispara sua inserção no circuito, através de matérias que seguem uma a outra, e cuja referência principal se constitui o boletim médico emitido. $\mathrm{O}$ núcleo da matéria não anuncia que o ex-presidente tem um câncer, mas já avança com um

\footnotetext{
${ }^{2}$ http://g1.globo.com/ 
informe complementar, que é associado a tal enfermidade, ao dizer que ele fará quimioterapia: “BOLETIM MÉDICO 29/10/2011 - 11h00. O Ex-Presidente da República, Sr. Luís Inácio Lula da Silva realizou exames no dia de hoje no Hospital Sírio-Libanês, em São Paulo, tendo sido diagnosticado um tumor localizado de laringe. Após avaliação multidisciplinar, foi definido tratamento inicial com quimioterapia, que será iniciado nos próximos dias. $O$ paciente encontra-se bem e deverá realizar o tratamento em caráter ambulatorial. A equipe médica que assiste o Ex-Presidente é coordenada pelos Profs. Drs. Roberto Kalil Filho, Paulo Hoff, Artur Katz, Luiz Paulo Kowalski, Gilberto Castro e Rubens V. de Brito Neto.

Dr. Antonio Carlos Onofre de Lira - Diretor Técnico Hospitalar e Dr. Paulo Cesar Ayroza Galvão - Diretor Clínico"

A primeira intervenção do "sistema midiático jornalístico" dispara o acesso imediato de falas dos internautas, no seu respectivo site, cuja ênfase se estrutura em torno de dois eixos semânticos: de um lado, as notas de solidariedade: "Lula foste sempre um lutador, não vai ser agora que vais fraquejar. Lute com todas as forças e não se deixe abater. Coragem com muita fé, companheiro". De outro, registros de ataque fazem emergir um outro ângulo, ao politizar o acontecimento; a maioria das mensagens cobra do ex-presidente coerência, com sua origem e suas convicções, recriminando-o por não ter procurado os serviços médicos de natureza pública, como os do SUS (Sistema Único de Saúde), para fazer o tratamento da doença: "Lula dê o exemplo, você não é do povo. Vai para o SUS!"; "Se o Lula é do Povo, por que ele não vai no SUS?"; Ironizam a opção de Lula pelos serviços hospitalares privados: "O milionário Lula não quis ir procurar os serviços do SUS onde o povo que o elegeu vai sofrer humilhação em fila durante a vida inteira! Deveria também procurar a medicina de Cuba que, segundo os esquerdistas, é um exemplo. Incoerência. Isto é PT’'. Outras mensagens sugerem, também em caráter irônico: "Vamos criar uma campanha Lula no SUS. Lulando $S U S$ ". Afloram também discursos em defesa do ex-presidente, ensejando o aparecimento de fórum de discussão: "O que mais me deixa perplexo são alguns tipos de comentários bizarros, sem noção que vi aqui. A culpa não foi do Lula, o país vem neste caos há séculos desde a época da ditadura. (...) Quanto ao estado do ser humano Lula, espero que Deus tenha misericórdia e lhe conceda bênçãos de uma cura". 


\section{b) A enfermidade, segundo as revistas}

As mídias não poderiam ficar a "espera do acontecimento,mas a cobertura mais investigativa somente acontece uma semana, após a eclosão, quando as revistas entram no circuito (09/11/2012). Tentam resolver a defasagem se apropriando da enfermidade, segundo estratégias e regras privadas presentes nos dispositivos de enunciação específicos a cada uma. Destacam o fato em sua principal instância de contato com o leitorado - as capas - de onde convidam o leitor para "ver" a doença que vai ser semantizada, segundo as cenas construídas por cada uma delas, e cujas marcas deste trabalho já aparecem nos títulos das matérias: "VEJA", no seu principal título de capa, elege como ângulo: "Os bastidores da luta de Lula contra o câncer", uma espécie de "resposta" a estratégia discursiva do IL, chamando atenção para o fato de que a instância de mediação jornalística não está fora do circuito, uma vez que a enfermidade do presidente está ali no relato por ela apresentado. Ao chamar atenção, por esta estratégia autorreferencial de sua cobertura, procurava também autolegitimar o seu tipo de entrada em cena, citando o lugar de onde estaria falando sobre o caso: os bastidores. "ISTO É" que, ao invés de enfatizar os bastidores da luta do ex-presidente, enuncia no seu principal título de capa, uma singular contenda na qual Lula está envolvido: "A grande batalha de Lula". Se VEJA promete os "bastidores" da luta de Lula - algo para o que convida também o leitor a ver nas páginas internas - ISTO É já antecipa na própria capa detalhes daqueles bastidores: elementos, cenários, situações que envolvem tal "pugna". Para tanto, enuncia um elenco de "micro acontecimentos" sobre a batalha de Lula: "A comoção nos bastidores da luta do ex-presidente contra o câncer"; "O momento em que dona Marisa se desesperou e as reações dos irmãos de Lula"; "A hesitação e o medo do ex-presidente antes do diagnóstico"; "Os primeiros dias após o tratamento"; "Os desdobramentos políticos do caso para o PT e para o Brasil". VEJA e ISTO É oferecem ao leitor, de modos distintos, a sua condição mediadora para que tenha acesso à enfermidade: VEJA convida-o para "conhecer os bastidores" e ISTO É expõe, ali mesmo na capa, tais cenas, sem necessidade do leitor nelas mergulhar. Uma terceira publicação, "ISTO É GENTE" - um suporte que cobre a vida das celebridades - já subordina Lula a operadores dos seus "arquivos": não enfatiza a enfermidade e no lugar deste ângulo, transforma o ex-presidente em mito. Com a enfermidade aparecendo em segundo plano, ele é inserido na "galeria dos mitos": "Lula, 66 anos, $O$ mito e o câncer". O subtítulo da matéria ao invés de falar da doença, prioriza depoimentos de 
personalidades sobre o enfermo. Abandonando o ângulo dos bastidores, "CARTA CAPITAL" e "ÉPOCA", contaminadas pela ambiência midiática, examinam a repercussão da enfermidade junto aos internautas, dialogando também com a cobertura sobre o assunto,por parte dos jornais diários. A primeira, através de matéria de capa "Lula, a doença e a estupidez", analisa o tom da reação dos internautas, sobretudo suas críticas a respeito das escolhas dos serviços médicos feitas por Lula. A segunda, faz do tema da reação dos internautas - a qualidade dos serviços prestados pelo SUS e a sua não escolha por parte do expresidente - a chamada de sua matéria de capa: "O SUS e o preconceito".

A disponibilidade de fotos de Lula, veiculadas pelo IL, onde registra-se o tratamento quimioterápico no hospital, não inibe, porém, o trabalho de produção de sentido das mídias jornalísticas. Tais imagens não poderiam circular sozinhas e, tão pouco atestar de modo exclusivo, a existência da enfermidade. A partir de outros expedientes, as mídias jornalísticas procurariam as marcas de sua evidência, segundo a mobilização de outras construções. Utilizam-se, para tanto de várias estratégias: Arquivos jornalísticos nos quais imagens de Lula foram, em momentos anteriores, sistematicamente utilizadas para "alimentar" coberturas anteriores, - especialmente aquelas que foram trabalhadas pelos "capistas" - foram acionados a fim de que imagens pudessem estar a serviço da construção da enfermidade tecida pela produção jornalística. Deste trabalho, resultam as capas das edições das semanas nas quais revistas apresentam as imagens de Lula, retirada dos arquivos, mas desviadas por operações enunciativas específicas, para serem associadas à enfermidade. Nelas, Lula é apresentado entre a contrição e a resignação (VEJA, imagem 1); mergulhado em um olhar suplicante (Carta Capital, imagem 2); ou em um olhar perdido (ISTO É, imagem 3); seu corpo é exposto para ser olhado e "vasculhado" por nossos dispositivos interpretativos (Época, imagem 4); e, de perfil, com um olhar levando-o para fora de cena (ISTO É Gente, Imagem 5). 


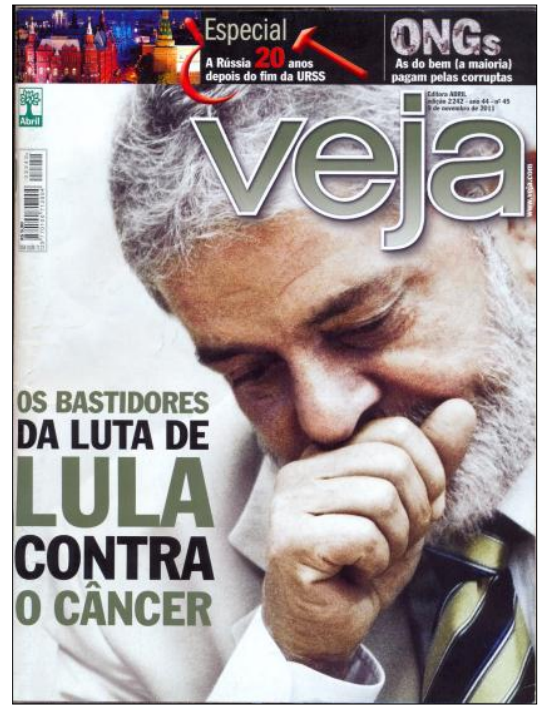

Imagem 1

Revista Veja, 09/11/2011

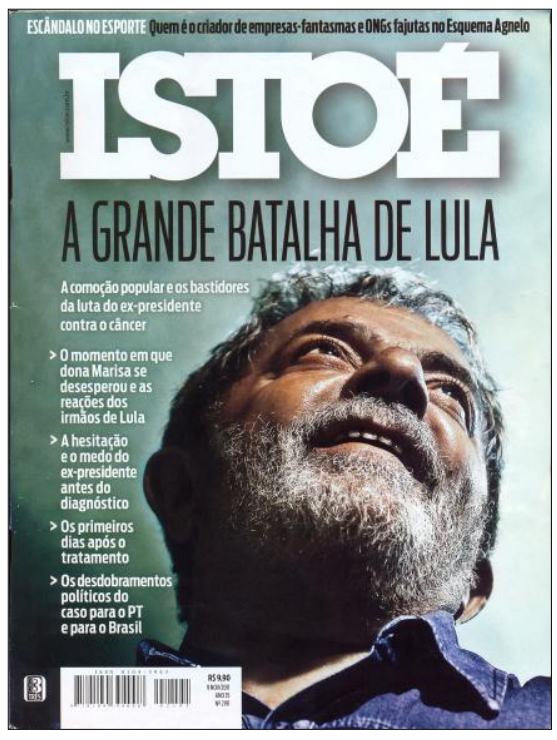

Imagem 3

Revista Istoé, 09/11/2011

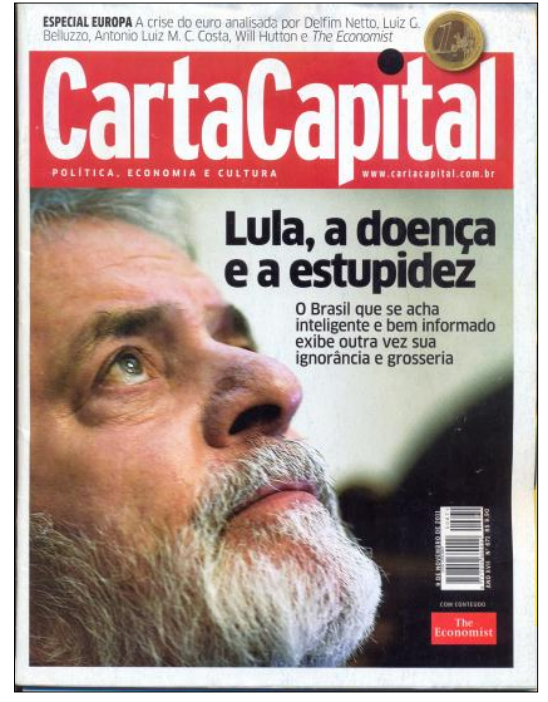

Imagem 2

Revista Carta Capital, 09/11/2011

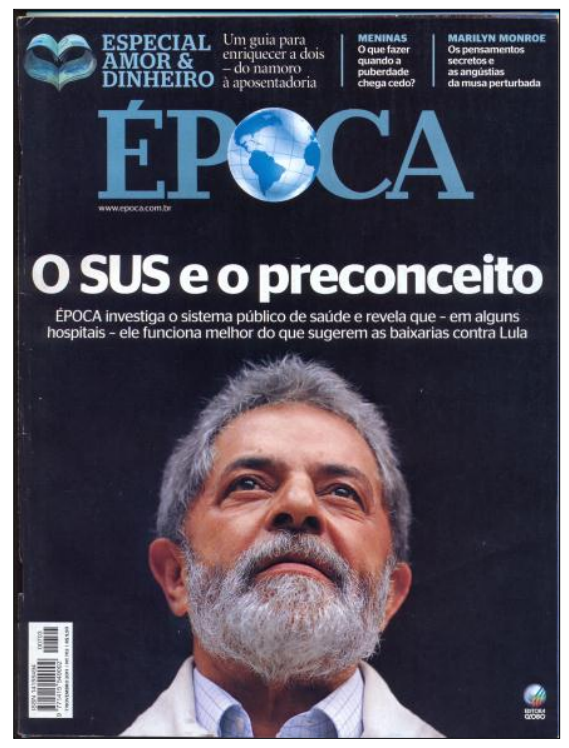

Imagem 4

Revista Época, 07/11/2011 


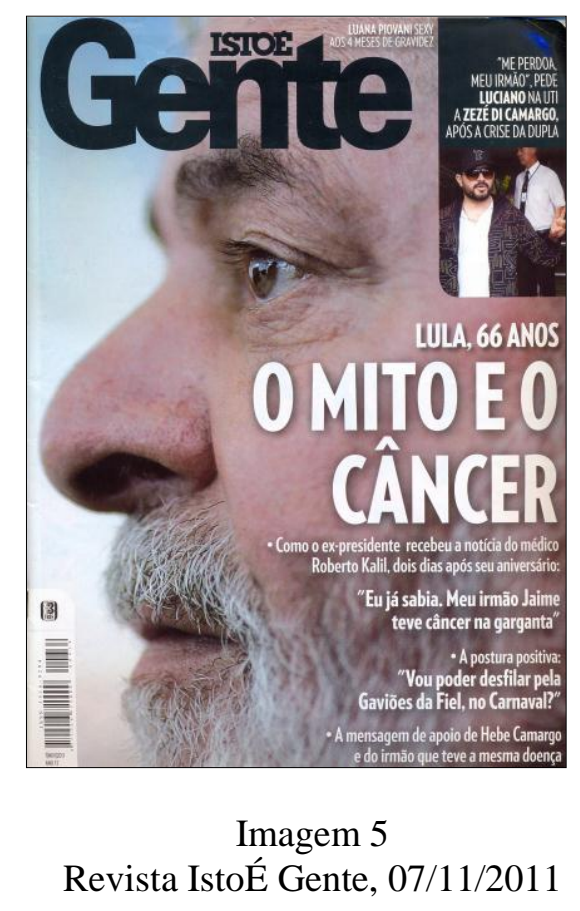

Lula é também convertido em um paciente midiático através de dispositivos interpretativos - os infográficos nos quais os relatos jornalísticos diagnosticam, descrevem, predizem, desenvolvem por conta própria um trabalho interpretativo sobre a doença. Em todas elas, as infografias se expandem por mais de uma página e são constituídas por imagens de Lula sobre as quais textos - diagramas ou outras animações - são sobrepostos, desenvolvendo operações enunciativas que privilegiam aspectos explicativos sobre a enfermidade. A conjugação de textos e imagens (fotos ou silhuetas) transformam Lula em um "paciente" do "trabalho terapêutico midiático" que, assim, vasculha o corpo do enfermo. VEJA (imagem 6) enfatiza explicação sobre o que vem a ser o câncer de laringe, através de "Box" no qual narra as suas causas. Destaca o tamanho do tumor, a radioterapia, como segunda fase do tratamento, e a natureza dos efeitos colaterais. ISTOÉ revela a região do corpo afetado pela doença, a partir de imagem da cabeça e tronco de Lula (imagem 7), e também em um "Box" define o "tumor do ex-presidente". Nela explica o que chama o de "esquema da quimioterapia" e prognostica seus efeitos colaterais. ISTO É GENTE apresenta uma infografia mais sucinta (imagem 8) e, apoiada sobre imagem de parte do corpo de Lula, indica os riscos do tratamento sobre a laringe e como estes afetam a voz do paciente. ÉPOCA, repete operações de outras revistas, e através de um Box, (imagem 9), dividido em três 
blocos: no primeiro, através de uma silhueta de Lula comenta a natureza do tumor que o afeta. No segundo, didatiza como será feito o tratamento, fixando, inclusive, o número de sessões de quimioterapia, e chamando atenção dos possíveis (sete) efeitos colaterais. E no terceiro, reúne informações sobre o diagnósticos - causas e sintomas mais frequentes, bem como o respectivo tratamento a que Lula se submeterá.

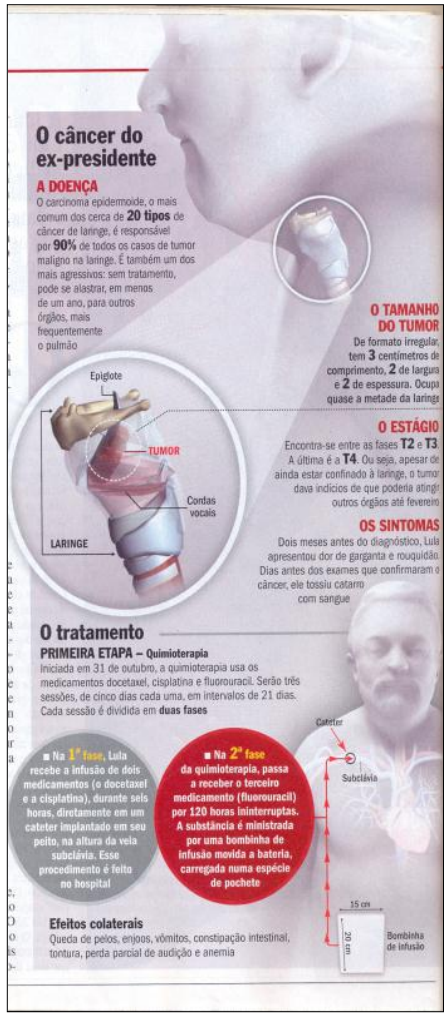

Revista VEJA

$(09 / 11 / 2011)$

Imagem 6

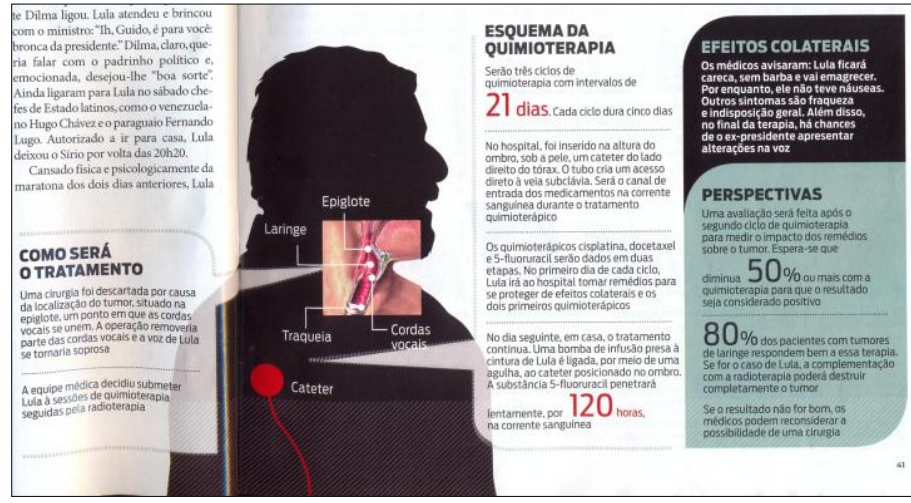

Revista Isto É (09/11/2011)

Imagem 7

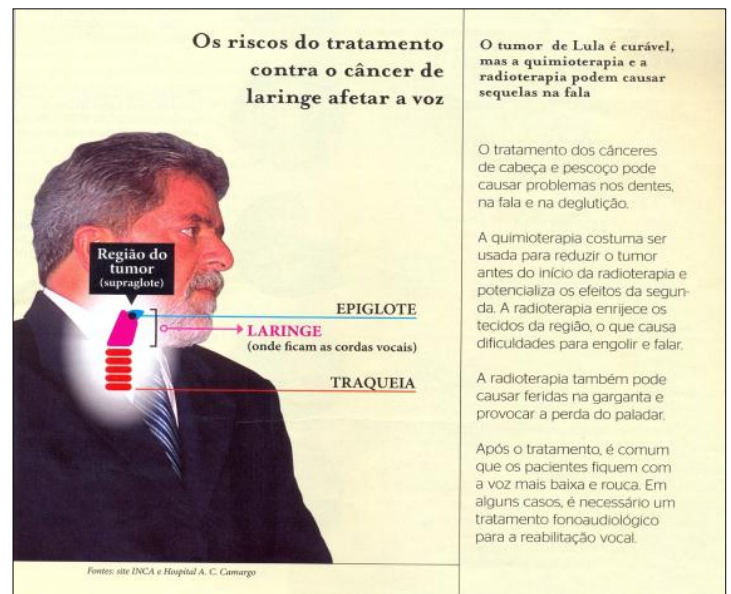

Revista Isto É Gente (07/11/2011)

Imagem 8 


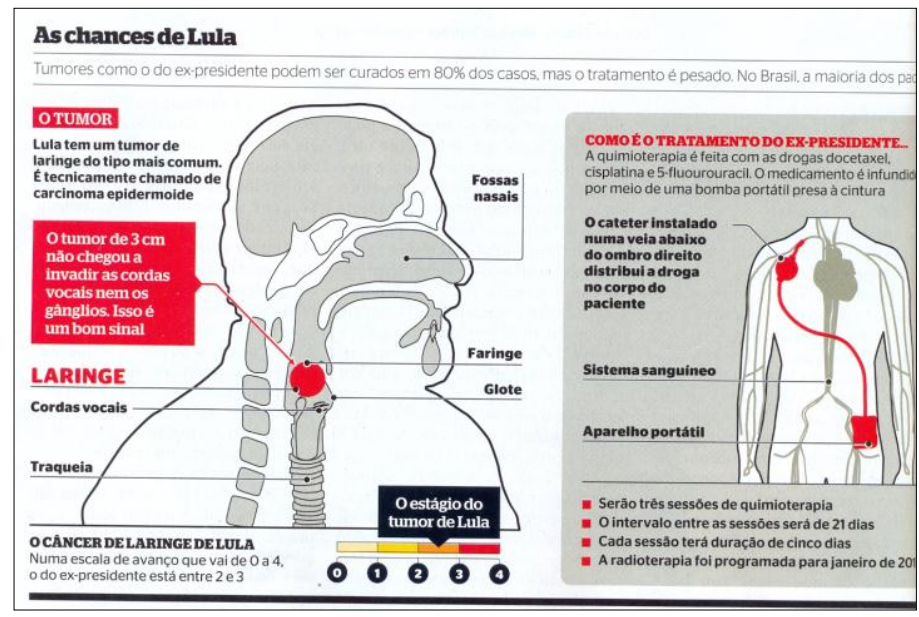

Revista Época $(07 / 11 / 2011)$

Imagem 9

Enquanto uma dos principais operações de leitura das mídias jornalísticas, as infografias não são apenas um recurso didático. Mais que isso, é através delas que as revistas se "rivalizam"- através deste trabalho autorreferencial - com as abordagens médicas ao produzir discursos dos quais emergem as suas próprias noções sobre a enfermidade.

\section{c) $O$ "embate" entre mídias, colunistas e leitores na "zona de interpenetração"}

Se os meios digitais possibilitam um acesso dos comentários dos leitores ao processo de circulação dos discursos, ensejam apenas em parte, nesta instância, o trabalho dos receptores. Sabe-se que o diálogo entre sistema midiático e receptores, não se estabelece apesar dos mesmos se encontrarem no âmbito da "zona de contatos". O que se observa são diálogos entre receptores, atividade esta que certamente, é apenas assistida pelos atores midiáticos, em produção. Mas poder-se-ia dizer que em uma outra instância, se produzem outros efeitos deste processo de circulação de discursos; naquela onde comentários feitos pelos receptores, no site do G1, são “capturados" e correferidos em outras mídias, em espaços como editoriais, colunas, etc. Ou seja, discursos inseridos em diferentes suportes se contaminam ou, servem de condição de produção para outros discursos.

As manifestações dos internautas sobre as condições de internação de Lula e a cobertura de mídias sobre elas, são objeto de editoriais, como o da "Carta Capital"9.11.2011: "há uma conexão evidente entre as malignidades extraordinárias assacadas das 
moitas da internet e os comportamentos useiros do jornalismo no Brasil". Numa espécie de diálogo indireto com outras mídias jornalísticas descreve, em termos críticos o comportamento de colunistas e de emissões radiojornalísticas, especialmente aquelas que interpelam "quem paga o tratamento de Lula". A contenda entre internautas também se manifesta entre jornalistas. Alguns deles fazem a defesa de Lula, especialmente a estratégia por ele adotada para midiatizar a enfermidade, conforme o artigo "O exemplo de Lula" (Isto É, Leonardo Attuch, 9/11/2011): “O vídeo em que Lula agradece ao povo brasileiro pela solidariedade empenhada (...) diante de sua doença, que foi disponibilizado pelo Instituto Lula, é talvez a peça mais perfeita de comunicação já feita na historia do país". Os leitores se fazem presentes também nas secções especializadas das revistas, como a "Carta do Leitor". Uma semana após a descoberta do câncer, nas edições de 16/11/2011, os leitores voltam ao debate em torno do tema da midiatização da doença. Num primeiro registro, em VEJA, elogiam a cobertura sobre o assunto feita pela revista, em edição anterior , através de uma manifestação correferencial: "Precisa a reportagem". No segundo, elogia-se a estratégia de midiatização assumida pelo próprio ex-presidente: "Fiquei satisfeita ao constatar que o expresidente Lula divulgou a notícia de sua doença de forma clara, sem ocultá-la. Isto vai ajudar a todos". No terceiro, aparece um comentário critico sobre um dos ângulos trados pelos jornais: “Assustou-me muito, mais do que nas últimas eleições, o comportamento de certas pessoas na cobertura da doença do nosso ex-presidente. Sei que isso, infelizmente não é novidade (...). A (...) âncora colocou no ar a opinião de um comentarista político, de uma revista de circulação nacional, que sentenciou, de forma fulminante: 'Agora Lula vai saber que não é imortal'. Como se o ex-presidente estivesse morto. Não suportei, desliguei o rádio e segui minha viagem". (Cartas Capitais, 9/11/2011).

Observa-se nesta etapa que o acontecimento se constrói em três ângulos que se desdobram, como efeito do processo de circulação: o registro de um primeiro relato, no sentido de evitar que as mídias jornalísticas digam antes; um segundo que caracteriza a apropriação e transformação do acontecimento através de estratégias midiáticas-jornalísticas; e o terceiro corresponde a emergência de multiplicidade de acontecimentos e que diz respeito às construções dos internautas, derivadas de acontecimentos que foram construídos em outros estágios do processo de circulação. 


\section{Fase 2 - A antecipação dos efeitos quimioterápicos ${ }^{3}$}

Nas últimas semanas de novembro, novas imagens de Lula (imagens 10, 11 e 12) ${ }^{4}$ são feitas em “primeira mão “ pelo fotógrafo do Instituto Lula e disseminadas no próprio site daquela entidade. Produzidas segundo postulados midiáticos, captam momento de uma espécie de "cena familiar", a ser compartilhado com os que se encontram na ambiência da midiatização. Lula e sua mulher "deixam-se ver" não para uma "pose" que vai compor um álbum de família, mas para uma sequência de fotos. A imagem 10 mostra - a semi debruçada sobre a cabeça do marido, fazendo a barba dele e vestindo uma camisa de manga longa que traz a altura do peito, uma mensagem sobre a campanha "Contra o Câncer de Mama". Na imagem 11, mais próxima a cabeça de Lula, sua mulher afaga, levemente, o rosto de Lula compartilhando com ele, num gesto de sorriso, o momento mostrado pela operação fotográfica: a barba desfeita. A imagem 12 transforma o enquadramento da foto anterior, aproximando com mais nitidez para apreciação do receptor - além do sorriso compartilhado pelo casal - a consumação da queda do cabelo e da barba do ex-presidente. O trabalho fotográfico não se trata de um mero "ato testemunhal", mas significa a intervenção da atividade midiática na dinamização de uma cena que se engendra envolta por valores e referencias de intimidade familiar; seu objetivo é, intervindo sobre o corpo do paciente, antecipar as marcas que sobre ele se manifestariam, tempos depois, como efeito do tratamento quimioterápico, ao qual, muitas vezes, se submetem pacientes com câncer.

\footnotetext{
${ }^{3}$ Algumas das questões aqui examinadas foram refletidas em "Midiatização da enfermidade de Lula: Sentidos em circulação em torno de um corpo significante”. In: Jeder, J; Matos, M.A; JACKS, N. (orgs). Mediação e Midiatização. Salvador: EDUFBA/ Brasília: Compós, 2012.

${ }^{4}$ O Instituto Cidadania anuncia a autorização de reprodução livre das imagens no site. Disponíveis em http://www.institutolula.org/2011/11/dona-marisa-corta-cabelo-e-barba-do-ex-presidente-lula/
} 


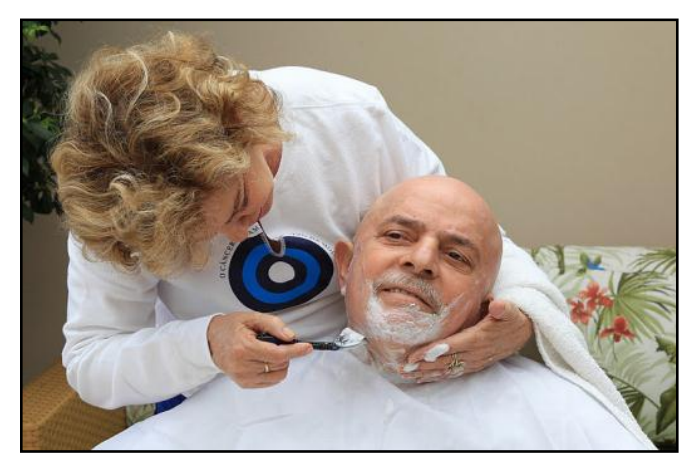

Imagem 10

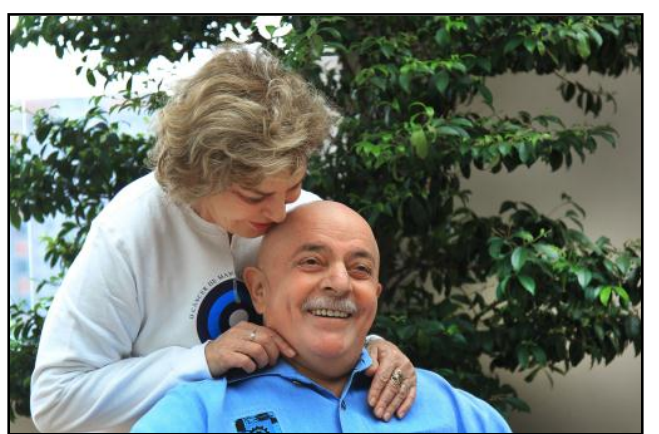

Imagem 11

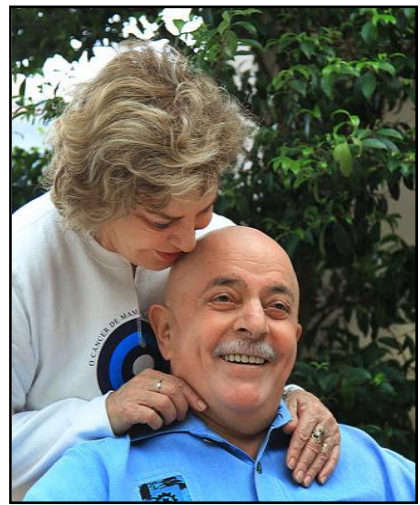

Imagem 12

\section{O acontecimento nas mãos das fontes e/ou de outros campos sociais}

Estas três manifestações chamam atenção para novas operações de midiatização da enfermidade do presidente Lula, cujos discursos ingressam num processo de circulação, a partir de uma outra operação enunciativa posta em prática pelo próprio dispositivo que funciona, independente da mediação dos próprios meios. Diferentemente da "sociedade dos meios", na qual o caso é entregue a estruturas mediacionais clássicas, como serviços de relações publicas, assessoria de imprensa, ou por porta-vozes - como foi o caso da doença e morte do presidente Tancredo Neves (Fausto Neto, 1988) - na sociedade em vias de midiatização, o acontecimento é uma resultante de intervenções que resultam menos de mediações, e mais de um trabalho de atorização que se faz em meio a outros rituais de produção de sentidos.

Dois estudos anteriores realizados, recentemente, sobre os processos de midiatização de acontecimentos, mostraram como diferentes práticas sociais de campos distintos - grupo criminal e instituição policial - se apropriam de lógicas e operações midiáticas para produzir midiatização de fatos de seu interesse. Suas estratégias visavam anunciabilidade de matérias nos meios, mas, diante da impossibilidade de fazê-la pelas mediações clássicas, produziram outras condições de midiatização, nas quais seus agentes se converteram em peritos e atores (Fausto Neto, 2006; Fausto Neto, 2007). O processo de midiatização da enfermidade do expresidente Lula pertence ao universo destes casos, acima aludidos. Porém, aparece com mais complexidade na medida em que seu objetivo principal não visa apenas, o acesso aos meios. Mas, uma outra modalidade ao construir protocolos e fluxos de produção e de circulação do 
acontecimento, que se desenvolvessem a margem, ou sofrendo menor grau de condicionamento das mediações midiáticas, propriamente ditas. Talvez no bojo da estratégia, estivesse posta a questão de enfraquecer o status das mídias - enquanto principal "elo de contato" entre as instituições e a sociedade. Tal possibilidade seria favorecida largamente, pelos novos processos de produção e de circulação de discursos ensejados pela "arquitetura comunicacional" da sociedade em vias de midiatização.

\section{O dispositivo preparando sentidos...}

Certamente, muitas imagens foram "capturadas" pelo dispositivo comunicacional do IL, mas apenas três integraram enquanto matéria significante, o "pacote" fotográfico ao texto explicativo. As imagens mostradas e disseminadas sobre a queda do cabelo e barba do Lula para o ambiente midiatizado fogem aos tipos usuais de registros fotográficos: a foto-artística; a foto-reportagem; e foto-amadora (Verón, 1994), uma vez que não são imagens que se destinam a galeria; tão pouco capturadas de um real, usualmente recuperadas pela fotojornalística; e nem ainda, uma foto amadora, produzida sob encomenda, ou por caso. Pertencem a um novo tipo de matriz de discursividades, cujas condições de produção estão relacionadas com a existência de um dispositivo que não está vinculado a instituições midiáticas, no sentido restrito, mas que é afetado pelas lógicas e da cultura dos meios sobre as quais se faz a "captura do acontecimento". As imagens não são apenas registros cedidos por um serviço especial de comunicação para as mídias, conforme acontece, usualmente, com as assessorias de imprensa. Nascem e circulam no seio de outro tipo de prática social, cuja instituição que as produz elege um dispositivo operacional, atravessado por protocolos de midiatização, para desenvolver estratégias a partir de lógicas e postulados próprios, em relação ao universo dos meios. Não se trata de uma "operação abstrata" e que, portanto ignore a presença nela de outras práticas sociais. Conforme a análise mostra, operações do campo político ali se fazem presentes, mas atravessadas por lógicas do campo das mídias. Um determinado "real" chama atenção através desta operação fotográfica: o registro que documenta um fato, mas que sofre injunções de determinadas condições de produção e de circulação; o acontecimento aqui é registrado para que aí, neste momento, se produza a antecipação dos efeitos quimioterápicos. E, ao mesmo tempo a disseminação da prova de sua 
efetivação. Para tanto, o corpo do presidente é paciente, mas também ator desta operação.

Em termos de circulação, o "pacote" das três fotos não foi apropriado em sua íntegra pela mídia. É “desmontado” pelos processos de edição dos velhos e novos meios, sendo submetido à novas semantizações em função dos contextos, e outras injunções dos processos de circulação e de natureza editorial. As fotos recebem vários status: servem como decoração de matérias; destacam o ato inusitado de raspagem da barba, em si; chamam atenção para o novo visual do presidente; enfatizam a cena da intimidade que envolve o acontecimento, em suma seguem outros passos constituídos por múltiplas operações de sentidos. É neste momento, que o jornalismo passa de uma posição receptora para uma outra atividade de leitura, ao se apropriar dos materiais e neles fazendo várias intervenções. Uma delas se caracteriza pelo modo enfático como enuncia o "lugar desencadeador" o acontecimento: "na tarde de quarta-feira, o Instituto Cidadania, do petista, divulga uma foto em que mostra Lula sem barba e cabelo" (ZH, Clicrbs, 16/11/2011 - grifo nosso). Outras operações são feitas e dentre elas, uma convergência: ratificar pela repetição em vários títulos e matérias, do operador de identificação antecipar, a origem e o status do acontecimento. Numa espécie de "diálogo" com o site do IL, as primeiras páginas de sites e de jornais recuperam este significante, como um operador central que vai nortear o trabalho explicativo de suas matérias sobre este episódio: "Em tratamento, ex-presidente antecipa a provável queda do cabelo e removeu a barba que o caracterizava" (ZH, 17/11/2011); "Lula sem barba e cabelo. Expresidente se antecipa aos efeitos da quimioterapia" (Diário Gaúcho, 17/11/2011); "Em seu apartamento, ao lado da mulher, o ex-presidente aparece usando só bigode, ele antecipa aos efeitos do tratamento com quimioterapia e pediu a Dona Marisa (...) que fizesse o papel de barbeiro" (FSP, 17/11/2011 - grifo nosso). Já nos sites propriamente dos jornais se dão as seguintes operações enunciativas:

a) O ex-presidente Lula (...) se antecipou aos efeitos do tratamento contra o câncer na laringe. (ZH, Clicrbs, 16/11/2011)

b) Em tratamento contra o câncer, Lula corta cabelo e barba. Ex-presidente se antecipa a queda de cabelo decorrente do tratamento (...) (Folha de Londrina, 17/11/2011);

c) Sem barba, Lula acaba com marca de uma era. Para tratar do câncer, expresidente se antecipa a químio, muda visual e raspa também a cabeça. (O Estado 
de São Paulo, 17/11/2011);

d) Lula raspa barba e cabelo e muda imagem de décadas (Diário Popular, SP, 17/11/2011);

e) Lula corta barba e cabelo e antecipa efeito colateral de químio. (Extra, $16 / 11 / 2011)$

f) Lula aparece sem barba e cabelo pela primeira vez após início da químio. (Correio Brasiliense, 16/11/2011)

g) Lula se antecipa e raspa barba e cabelo. (O POVO (CE), 17/11/2011)

h) Lula sem cabelo e barba, em imagem divulgada pelo Instituto Lula, ONG do expresidente. (O IMPARCIAL, 16/11/2011)

Conforme os títulos a ação de antecipar é semantizada através de várias construções feitas nos títulos e matérias, e a maioria delas desenvolve algum tipo de interpretação: Anuncia-se a antecipação nos tempos passado ou no presente, através de diferentes ênfases: explicam superficialmente os motivos pelos quais Lula aparece sem barba (f) Ou, simplesmente registram a antecipação $(\mathrm{g})$; associam a antecipação ao tratamento, mas, de modo genérico (b); relaciona-se claramente a queda da barba com a químio (e); fazem alusões aos efeitos colaterais, mas sem detalhá-los (e). Os exemplos (c) e (d) exploram outras construções, associando a raspagem do cabelo com o fim e mudança de uma era ("as imagens de uma década").

Uma operação enunciativa mais complexa (uma modalidade de "jornalismo investigativo", a seu modo), é realizada pelo portal G1/Política que mostra pesquisa: "Veja os diferentes visuais de Lula ao longo dos anos" - desde jovem sem barba, até a raspagem do cabelo e barba, 36 anos após, antecipando-se aos efeitos da químio. (G1/Globo, 17/11/2011). A operação trata de mostrar o que seria uma espécie de "percurso" de aspectos visuais da fisionomia de Lula, servindo para lembrar que há sempre um arquivo, enquanto dispositivo, a espera para dar forma aos sentidos...

Se a tríade das fotos é desfeita, e as imagens do corpo de Lula viram pedaços como efeito do trabalho de enunciação das mídias, ao dar forma aos novos corpos das imagens do ex-presidente, algo das "injunções" do trabalho enunciativo do IL ingressa e dissemina-se “nas construções jornalísticas” e, é por elas confirmado: o relato da antecipação dos efeitos, 
mas, sobretudo o registro que remete à autoria do ato de antecipar. De certa forma, o reconhecimento deste ato no âmbito da enunciação midiática, serve de prova para co-validar o argumento segundo o qual a midiatização do acontecimento não é uma decisão unilateral e exclusiva do jornalismo. Ele está nas mãos de muitos atores e é tecido em meios a complexos processos, dentre os quais, aqueles nos quais o jornalismo co-referencia enunciações que vem de outro lugar.

\section{Derivações de sentidos $x$ sentidos em derivações...}

Neste item fazemos algumas descrições sobre o "contato" que os receptores estabelecem com os discursos em circulação (os do site do Instituto Lula e os das mídias), através de textos por eles enviados. Aborda-se tais contatos através de três níveis de trabalho enunciativo: a) aqueles comentários em torno do ato de mostragem (que estamos chamando do trabalho discursivo de midiatização das imagens de Lula, por parte do dispositivo tecnoinstitucional); b) comentários sobre as (novas) imagens do corpo do presidente; e c) comentários que geram associações derivadas da midiatização destas imagens.

O funcionamento desta "zona" no que diz respeito às interações entre os internautas e o IL, parece mais restrito, uma vez que nela se dá apenas acesso de determinados tipos de personalidades públicas e celebridades (artistas, políticos,etc), através de mensagens que se reportam à enfermidade ou se solidarizam com o ex-presidente:

“Caro amigo Lula, eu e meus amigos estamos aqui torcendo por você. Temos certeza que tudo de ruim vai passar o mais breve possível. Que os anjos e todas criaturas do céu, tomem conta de nosso presidente, para nossa alegria. Um beijo pra Dona Marisa e um abração pra você e muita sorte. Milton Nascimento. Rio de Janeiro, 17-11-11"

Sobre o primeiro nível - o ato de midiatização da raspagem da barba e do cabelo é comentado pelos internautas, através de mensagens postadas em sites de suportes jornalísticos, nas quais fazem críticas ao fato. Há "discursos de ataque" ao modo como a enfermidade é midiatizada. Evocando vários tipos de explicações associadas a um determinado imaginário político: "Uma vergonha usar a doença assim” (Norma, ZH, Clicrbs, 18/11/2011). Ou: "Segundo dizem ta levando $R \$ 1$ milha (milhão) da Gilette. Agora tem a pergunta: como utilizar em propaganda vão ter que ter muita criatividade" (Observador 
Mineiro, O Estado de Minas, 1611/2011). Este último comentário provoca uma segunda reação: "até na doença este cidadão quer enganar o povo, quer dizer que a mulher dele com um simples aparelhinho de 02 lâminas raspou o cabelo a zero e tirou a barba. Quem for barbeiro sabe do que estou falando" (Arilson Sartorado, O Liberal 16/11/2011). Como estratégias de contraposição, internautas fazem a Lula um "ato de desagravo": "Cortar o cabelo ou tirar a barba, não quer dizer nada, pois o homem que você é, independe de barba ou cabelo, sempre será um homem do povo, do nosso povo brasileiro. Abraços de um eterno agradecido do seu trabalho" (Marcio rego, O Povo, 17/11/2011).

No $2^{\circ}$ nível, As impressões dos internautas sobre os efeitos da raspagem em relação às imagem do presidente, são realizados vários tipos de associações: aquelas com personalidades do mundo político: "Ficou o Sarney sem cabelos, porém na essência é igualzinho a ele" (Andre Luis, ZH, Clirbs, 16/11/2011). Ou então: "Engraçado, ele ficou a cara do ACM (Antonio Carlos Magalhães)” (Felipe, ZH Clicrbs, 16/11/2011). Lançam mão da contenda política: "Quando começarem as próximas campanhas eleitorais e acontecerem as carreatas alguém pode gritar: joguem bolinhas de papel neste careca safado" (Athos Martello, G1, 23/11/2011). Ficando ainda neste território, são taxativos, ao sustentar um certo discurso de oposição: “de cara limpa fica mais difícil mentir!” (Amaury, ZH, Clicrbs, 16/11/2011). Em contraposição com outras associações, aparecem mensagens de cumplicidade e também elogiosas: "Ficou bonito também, mas a grande beleza deste estadista está no seu interior" (Jalio Albuquerque, Correio Braziliense, 16/11/2011). Registram lamentação pela queda da barba, mas fazem elogios e cumprimentos ao presidente pelo apoio que recebe da mulher: "Fiquei triste ao ver o Lula sem a sua famosa barba, mas como eu sei que o poder de Deus é grande, ele vai se sair dessa. Uma torcedora. Parabéns por ter dona Marisa. Estou rezando por você." (Genelsa, O Povo On Line, 16/11/2011).

No $3^{\circ}$ Bloco - Associações derivadas da midiatização das imagens- observa-se, mediante comentários de várias modalizações, mensagens que fazem uma construção transversal do caso com outros episódios correlatos ao tema da saúde. Eles abandonam, na sua maioria, o tema da raspagem da barba e do cabelo, e relacionam o caso com as condições das políticas públicas do país, na área da saúde. De modo mais "analítico", desenvolvem avaliações comparativas: "No Brasil os cancerosos pobres morrem todos, pela falta de atendimento médico. Para que serve a constituição federal? para os ricos!" (Luiz Campos, 
Correio Braziliense, 21/11/2011). Ainda: "Quero que o Lula tenha pronta recuperação. Porém, lamento muito pelo fato da grande maioria do povo brasileiro não ter acesso ao mesmo nível de tratamento. Infelizmente se for depender da rede pública para uma doença tão agressiva o resultado vai ser a morte" (Marcos Perez, Correio Braziliense, 21/11/2011). Interpelam o presidente, a exemplo do que fizeram quando divulgadas as primeiras notícias de que Lula estava sendo tratado em hospital de alta qualidade: "Meu prezado Lula, por que o senhor não recorreu a um hospital do SUS? (Daniel Silva, Correio Braziliense, 21/11/2011). Em um tom mais interrogativo, mas de modo reverencial, mas talvez irônico, questionam: "Só uma pergunta: O Sr. Ex-Presidente Lula vai fazer seu tratamento pelo SUS?"(Susana, ZH, Clicrbs, 16/11/2011). Falam ao presidente encaminhando-o proposições: "Torço pelo ser humano LULA mas assim como ele pregava a igualdade entre os brasileiros ele deveria fazer o tratamento pelo SUS e saber o que o povo brasileiro de fato sente na pele" (Luiz Fernando, ZH, Clicrbs, 16/11/2011).

O espaço da interação também é utilizado para que o internauta conforte e se solidarize com o presidente. Relata-se casos de pessoas que contraíram a enfermidade familiares ou amigos -; sugerem também êxito no tratamento ao presidente, e manifestam carinho e apoio ao seu tratamento: "Queria levar até você lula, me permita esse tratamento, mas é que o tenho como amigo, não com a imponência de presidente, meus votos de plena cura e dizer que passamos por esse mesmo problema. Meu marido João Carlos Passini, teve câncer de corda vocal, fez 2 cirurgias por vídeo, que em nada resultaram, até que foi realizada a tradicional com corte cirúrgico, e isso já fazem uns bons 6 anos. Ele tem a voz restrita, mas fala e se comunica bem. ficou curado, então, quero levar esse depoimento, para dizer que tem cura, e a pessoa embora tenha restrições, tem vida normal. que deus esteja sempre junto a você e sua família. Tenha fé, só muita fé. Ela é a razão de tudo. Estou torcendo por você. Meu marido também fez radio e foram 33 sessões. Mas tudo passa. Força amigo. Fique com Deus. Um abraço”. (Maria Bernadete Castro Passini - O Povo Online, 16/11/2011). Politizam o tema comparando os que tratam o câncer em condições diferentes e denunciando o modo de morrer dos pobres: "Os pobres morrem sem assistência médica, pela sua própria culpa! elegem sempre os mesmos políticos que nunca fizeram nada." (...) "No Brasil os cancerosos pobres morrem todos, pela falta de atendimento médico. Para que serve a constituição federal? para os ricos!” (Luiz Campos, Correio Braziliense, 21/11/2011). 


\section{Notas em Conclusão}

A descrição das estratégias aqui apresentadas sugere como conclusão, algumas notas em torno dos seguintes aspectos:

Como mostramos o trabalho de enunciação sobre a enfermidade do ex-presidente Lula é formulado, inicialmente por uma instância não-midiática que se vale de lógicas de mídia, para que o acontecimento possa ser reconhecido pelo ambiente da midiatização. Já neste nível, observa-se acoplagens entre práticas discursivas, atividade que é possibilitada através de "feixe de relações" entre campos sociais; estes, por força do processo de circulação e da natureza de suas identidades, racionalidades e imaginários, desdobram a enfermidade noutros sentidos, muitos dos quais escapam a doença, enquanto tal. Estes fluxos, acoplagens e interações aqui descritas, estruturam o que chamamos de "realidade midiática", algo que, segundo nosso ponto de vista, transcende a noção luhmanniana de "realidade dos meios". Explicando: apesar dos meios aí se manifestarem, através de várias operações de autorreferência, correferência e de heteroferrências - o trabalho discursivo de constituição do acontecimento midiático é atravessado segundo processualidades tecnodiscursivas que são tecidas através de múltiplas instituições e atores (Fausto Neto, 2011), além dos meios, situadas na ambiência complexa da midiatização. Tal atividade de produção/disputa/circulação de sentidos se faz através de dinâmicas através das quais as complexidades de diferentes instituições - IL, mídias e receptores - são disponibilizadas, segundo ações se não convergentes, mas cooperantes. Ou seja, quando dinâmica de uma instância se vê penetrada e co-determinada por uma outra e vice versa. Trata-se de coocorrências enunciativas que põem à luz sua atividade da qual resulta a face visível do acontecimento. Graças ao processo de circulação de discursos, as instituições presentes nesta realidade, se interpenetram em uma atividade interacional, sendo que apenas parte deste trabalho é visível, via as marcas discursivas.

Em segundo lugar, devemos enfatizar o que representa o deslocamento do trabalho de autoralidade de produção do acontecimento, quando o Instituto Lula, através de uma estratégia autorreferencial, antecipa-se aos meios para anunciar a doença de Lula e os efeitos de sua quimiterapia. De um lado, a realização desta operação tem a ver com a "biografia midiática" do ex-presidente que, durante sua vida sindical e de presidente, lidou com as 
mídias segundo várias situações.

Num outro momento, Lula adere à forma, as "senhas" da midiatização, especialmente nas eleições de 2002, quando sua campanha gerida pelas lógicas de mídias, sepulta a retórica sindical (Fausto Neto; Verón, 2004). E, já na presidência, e, sem ameaçar tal poder mediador jornalístico, cria - para além do seu carisma - seus próprios "protocolos midiáticos" de contatos com a sociedade, algo que lhe vale o título de "presidente língua solta" (Fausto Neto, 2011). Mais recente, fora do governo cria seu staff comunicacional que tece a estratégia em analise e, que visa, justamente, através de operações midiáticas feitas às margens da mediação jornalística - antecipar o anúncio da sua doença e os efeitos de seu tratamento. Evidentemente, que tal estratégia não se funda numa racionalidade determinística, fazendo com seus sentidos fossem irradiados, unilateralmente, no processo de circulação dos discursos. Sua "pragmática comunicacional" se faz no contexto de complexidades e de relacionalidades, que reúnem a existência do outro, no caso, os campos sociais, através de suas práticas e estratégias, seja também o universo dos atores sociais. Sem este "prérequisito", seria impossível a midiatização da enfermidade, por parte do Instituto Lula, uma vez que: "para que a autopoiesis de uma operação possa ser efetuada, o meio \{enquanto ambiente \} deve garantir condições extremamente complexas" (Luhmann, 2009, p.269).

Em terceiro lugar, deve ser lembrado que apesar das condições de sua "gênese", o acontecimento se faz numa rede de conexões onde discursos se afetam e se co-determinam, através de acoplagens. Destas, muitas das suas operações permanecem invisíveis, mas também traços do seu processo aparecem, via discursos que circulam e que se contatam na “zona de Interpenetração" Destes resultam, pelo vasto trabalho de co-enunciação, sentidos que apontam a diversidade de vínculos que a organização social tem com a política, especialmente Lula, enquanto um corpo-significante. De um lado, vinculam-se com ele em torno da comoção, algo que talvez não pudesse ser diferente, mesmo entre aqueles que se anunciaram como adversários. Mas, veio também deste tipo de enunciação, a possibilidade de interpelá-lo, num quadro de interlocução que mostra como os receptores falam e fazem associações, chamando atenção para diversidade com que os bens sociais são apropriados de modo desigual, como por exemplo, os serviços de saúde e outras políticas. A comoção presente nos discursos de solidariedade, lembra o "modo de celebração" da vida, doença e/ou morte nas sociedades de características comunitárias, conforme faziam os antigos. Os 
discursos produzidos sobre a enfermidade se embatem, se singularizam, mas se codeterminam e se contaminam em torno de um "ato de celebração". A enfermidade enquanto acontecimento, é produzida e narrada por diferentes instâncias discursivas, e transformada em "micro acontecimentos" que se afetam e se atravessam, gerando muitas enfermidades, em torno de um não consenso discursivo. A recomendação feita por Lula aos quadros médicos e de assessores que o assistiram neste momento, no sentido de que tratassem a sua doença com devida transparência, foi também "contaminada" por muitas outras lógicas e racionalidades que nesta "zona de interpenetração" teceram outros significantes, para além do que inaugurou, como estratégia, o Instituto Lula.

Para concluir devemos enfatizar que se a doença eclode segundo as características comunicacionais aqui descritas, ela também se pulveriza conforme lógicas do próprio trabalho da comunicação. Ou seja, as duas operações feitas pelo Instituto Lula - antecipar a existência da doença e os efeitos sobre o corpo de Lula do tratamento quimioterápico - nascem de uma instância de auto observação que se volta para interferir sobre o "corpo midiático" evitando que fosse ele o anunciador e principal mediador da enfermidade, em primeira mão. Também uma intervenção sobre o universo das sintomatologias, salientando que, antes mesmo que o corpo revelasse os efeitos quimioterápicos, um outro "corpo" - de espessor comunicacional tratasse de presentificá-los. É no instante desta "pragmática" que sentidos são ofertados ao trabalho de leitura das instituições e da sociedade. A estratégia de midiatização não pode ser consensual, uma vez que sua atividade complexa se bifurca: de um lado, a oferta de sentidos, cujos objetivos devem ter sido voltados para redução de complexidades, etc. De outro, os entendimentos (não sabidos a priori) que dela se fará. Nestas condições, a operação comunicacional está aberta aos efeitos, enquanto acoplamentos: aqueles convergentes com suas lógicas e finalidades e/ou a aqueles outros que colocam outras possibilidades de entendimento sobre o acontecimento, à deriva inclusive do protocolo operado. Como o processo de comunicação "afeta", mas ao mesmo tempo "isola" os elos desta rede de produção de sentido (instituições, mídias e atores sociais), a interação sobre a qual esta dinâmica opera, está desprovida, por natureza, de elementos regulatórios... A circulação cuida de dinamizar o objeto. O acontecimento ao ser "passageiro" da atividade de circulação, mostra-nos que complexo processo de produção/circulação/recepção de discursos no qual enfermidade nasce, age, caminha, etc, é apenas um vestígio das possibilidades de produção de 
sentidos impostas pelo funcionamento da midiatização. $\mathrm{O}$ que parece, ser, provavelmente, verdade, é que os sentidos não se doam, e algo está à espera deles (Mouillaud, 1997) - como os dispositivos comunicacionais - para que um trabalho se faça sobre eles, atribuindo-lhes formas e inteligibilidades.

\section{Referências}

ARIÉS, P. (1988). História da Morte no Ocidente desde a Idade Média. Lisboa: Ed.Teorema.

AYALA, S. A. (2008). (Re) Leyendo en Internet. In : La trama de La comunicación. Vol. 13.

BARTHES, R. (2005). Cómo vivir juntos: simulaciones novelescas de algunos espacios cotidianos. Buenos Aires: Siglo XXI.

BRAGA, J. L. (2006). Mediatização como processo interacional de referencia. XV Encontro Anual da Compós, Bauru.

FAUSTO NETO, A. (1988). O Corpo falado. A doença e morte de Tancredo Neves nas revistas semanais brasileiras. João Pessoa: PROED-MEC.

FAUSTO NETO, A. (2006a) Será que ele é? Onde estamos? A midiatização de um "discurso proibido". In: Ícone, Ano 7, N.9, Dezembro.

FAUSTO NETO, A. (2006b) Observações sobre a midiatização da campanha eleitoral de 2006. Galáxia (PUCSP), v. 1.

FAUSTO NETO, A. (2007). A midiatização jornalística do dinheiro apreendido: das fotos furtadas à fita leitora. In: La trama de La comunicación. Vol. 12.

FAUSTO NETO, A. (2010). A circulação além das bordas. In: FAUSTO NETO, Antonio; VALDETTARO, Sandra. Mediatización, Sociedad y sentido: Diálogos entre Brasil y Argentina. Universidad Nacional de Rosario. Rosario.

FAUSTO NETO, A. (2011). Lula e a crise de 2008: fragmentos do discurso políticoanalisador. Revista FAMECOS, v. 18.

FAUSTO NETO, A. (2011). Enfermidade em circulação: sou eu mesmo que noticio o meu tratamento. In: Revista Galaxia, n.22. São Paulo, Dezembro. 237-249.

FAUSTO NETO, A. (2011) Lula, El presidente "língua-floja". La Trama de La Communicación, v.16. Rosário. 25-42. 
FIGURACIONES: teoria y critica de artes. (2011). Dispositivos mediáticos: los casos de las tapas de revistas em papel y en soporte digital, n.9 - dic, semestral.

JURGELENAS, P. (2008). La fotografía en términos de acción. In: La trama de La comunicación. Vol.13.

Le Dispositif: Entre usage et concept (1999). In : HERMÈS 25: Cognigion, Communication, Politique. Paris: CNRS Éditions.

LUHMANN, N. (2005). A realidade dos meios de comunicação. São Paulo: Paulus.

LUHMANN, N. (2009). A realidade dos meios de comunicação. São Paulo: Paulus.

MARTÍN-BARBERO, J. (2009). Uma aventura epistemológica. In: Revista Matrizes, v.1, n..2, São Paulo.

MATTANÓ, S. (2010). Imagen fotográfica: una cuestión de limites?. In: La trama de La comunicación. Vol. 14.

MOUILLAUD, M. (1997). O jornal: da forma ao sentido. Brasília: Paralelo 15.

PINTO, M. J. (1999). Comunicação e discurso: introdução à análise de discursos. São Paulo: Hacker.

SODRÉ, M. (2006). A antropológica do Espelho. Petrópolis: Vozes.

SONTAG, S. (1984). A doença como metáfora. Rio de Janeiro: Graal.

VERÓN, E. (1994). De l'image sémiologique aux discursivités : le temps d'une photo. In : Hermès, 13-14. Paris.

VERÓN, E. (1997). Esquema para el análisis de La mediatización. In: Diálogos, n.48. Lima: FELAFACS.

VERÓN, E. (2004). El cuerpo de las imagenes. Buenos Aires: Norma.

VERÓN, E. (2009). Semiotique Ouverte. Paris: Hachette. 
Original recebido em: 30/10/2012

Aceito para publicação em: 03/12/2012

Resumo sobre o autor

Antônio Fausto Neto é Professor Titular do Programa de PósGraduação em Comunicação na Universidade do Vale do Rio dos Sinos (UNISINOS) e Pesquisador $1 \mathrm{~A} \mathrm{CNPq.}$

Aline Weschenfelder é Mestre em Ciências da Comunicação pela Universidade do Vale do Rio dos Sinos (UNISINOS); Bolsista AT$\mathrm{NS} / \mathrm{CNPq}$. 